\title{
DESENVOLVIMENTO PROFISSIONAL DE PROFESSORES QUE ENSINAM MATEMÁTICA: A VISÃO DA GESTÃO ESCOLAR
}

\author{
Luciano Melo Santos ${ }^{1}$, Maria Elizabete Souza Couto ${ }^{2}$ \\ ${ }^{1}$ Mestrando em Educação Matemática pela Universidade Estadual de Santa Cruz - UESC, BA. Professor do Colégio \\ Modelo Luís Eduardo Magalhães e Professor da Secretaria Municipal da Educação de Canavieiras, BA. ORCID iD: \\ https://orcid.org/0000-0001-9482-1501 E-mail: lukamelo@gmail.com \\ ${ }^{2}$ Doutora em Educação pela Universidade Federal de São Carlos - UFSCar, SP. Professora Titular na Universidade \\ Estadual de Santa Cruz - UESC, BA, encontra-se credenciada no Programa de Pós-graduação em Educação em Ciências \\ e Matemática (PPGECM) e no Programa de Pós-graduação em Formação de Professores da Educação Básica (PPGE). \\ ORCID iD: https://orcid.org/0000-0002-0026-5266 E-mail: melizabetesc@gmail.com.
}

\section{RESUMO}

O presente artigo objetiva compreender como a gestão da escola vem organizando situações de desenvolvimento profissional dos professores no cotidiano das ações planejadas e desenvolvidas com os pares. É uma pesquisa de abordagem qualitativa, realizada em uma escola pública da rede municipal de ensino, que conta com a parceria de uma ONG e está localizada numa cidade da região sul da Bahia. Para coletados dados, realizamos entrevistas semiestruturadas com a diretora e a coordenadora pedagógica da escola. Da análise do material produzido nas entrevistas, foi possível compreender que o movimento proposto pela gestão para o desenvolvimento profissional dos professores, nesse caso, os que ensinam Matemática, é o de permitir, garantir, incentivar, participar e aproximar seus professores das fontes externas de formação, como Universidade e grupos de pesquisa, valorizando a cultura da escola, como local do ensino e da aprendizagem e das propostas apresentadas no Projeto Pedagógico da Escola, favorecendo o espaço da escola para que os professores possam discutir e colocar em prática essa formação e a reflexão da prática; o desenvolvimento profissional e a justiça social, como parte das condições de trabalho necessárias para o bom desempenho do professor na tarefa de promover a aprendizagem a seus alunos; e o diálogo com os professores que ensinam Matemática para avançar na construção do conhecimento matemático do aluno e do desenvolvimento profissional dos professores.

Palavras-chave: Desenvolvimento Profissional. Professores que ensinam matemática. Gestão da escola.

\section{PROFESSIONAL DEVELOPMENT OF TEACHERS TEACHING MATHEMATICS: THE VISION OF SCHOOL MANAGEMENT}

\section{ABSTRACT}

This article aims to understand how school management has been organizing professional development situations for teachers in the daily activities of actions planned and developed with peers. It is a qualitative research, carried out in a public school in the municipal education network, which has the partnership of an ONG and is located in a city in the southern region of Bahia. To collect data, we conducted semi-structured interviews with the school principal and pedagogical coordinator. From the analysis of the material produced in the interviews, it was possible to understand that the movement proposed by management for the professional development of teachers, in this case, those who teach Mathematics, is to allow, guarantee, encourage, participate and bring their teachers closer to external sources of training, such as the University and research groups, valuing the school culture, as a place for teaching and learning and for the proposals presented in the Pedagogical Project of the School, favoring the school space so that teachers can discuss and put into practice this formation and the reflection of the practice; professional development and social justice, as part of the working conditions necessary for the good performance of the teacher in the task of promoting learning to his students; and dialogue with teachers who teach 
mathematics to advance the construction of the student's mathematical knowledge and the professional development of teachers.

Keywords: Professional Development. Teachers who teach mathematics. School management.

\section{DESARROLLO PROFESIONAL DE PROFESORES DIDÁCTICOS DE MATEMÁTICAS: LA VISIÓN DE LA GESTIÓN ESCOLAR}

\section{RESUMEN}

Este artículo tiene como objetivo comprender cómo la gestión escolar ha ido organizando situaciones de desarrollo profesional para los docentes en las actividades diarias de las acciones planificadas y desarrolladas con los compañeros. Se trata de una investigación cualitativa, realizada en una escuela pública de la red de educación municipal, que cuenta con la colaboración de una ONG y está ubicada en una ciudad de la región sur de Bahía. Para recopilar datos, realizamos entrevistas semiestructuradas con el director de la escuela y el coordinador pedagógico. A partir del análisis del material producido en las entrevistas, fue posible comprender que el movimiento propuesto por la dirección para el desarrollo profesional de los docentes, en este caso, los que enseñan matemática, es permitir, garantizar, incentivar, participar y acercar a sus docentes. fuentes externas de formación, como la Universidad y los grupos de investigación, valorando la cultura escolar, como lugar de enseñanza y aprendizaje y de las propuestas presentadas en el Proyecto Pedagógico de la Escuela, favoreciendo el espacio escolar para que los docentes puedan debatir y poner en práctica esta formación y el reflejo de la práctica; el desarrollo profesional y la justicia social, como parte de las condiciones laborales necesarias para el buen desempeño del docente en la tarea de promover el aprendizaje de sus alumnos; y diálogo con los docentes que enseñan matemáticas para avanzar en la construcción del conocimiento matemático del alumno y el desarrollo profesional de los docentes.

Palabras clave: Desarrollo profesional. Profesores que enseñan matemática. Gestión escolar.

\section{INTRODUÇÃO}

As discussões sobre o desenvolvimento profissional dos professores vêm ganhando espaço no contexto da universidade e da escola, considerando que são espaços de construção e socialização de conhecimentos nos demais espaços, provocando situações de reflexões.

Nesse sentido, este artigo tem como objetivo compreender como a gestão da escola vem organizando situações de desenvolvimento profissional dos professores no cotidiano das ações planejadas e desenvolvidas com os pares. E com a indagação seguinte: Qual o movimento que a gestão da escola propõe para o desenvolvimento profissional de professores na escola?

Para a escrita, vamos apresentar material produzido em uma pesquisa em desenvolvimento, realizada com as ações do Grupo de Pesquisa e Estudos em Educação Matemática e Ciências (GPEMEC), em uma escola localizada em um bairro periférico de uma cidade do sul da Bahia. Na pesquisa, acompanhamos encontros de formação de professores que lecionam matemática nos anos iniciais do Ensino Fundamental e as reuniões de Atividade
Complementar $(\mathrm{AC})^{1}$ que acontecem, semanalmente, na escola para realização do planejamento das atividades pedagógicas a serem desenvolvidas em sala de aula.

Assim, este trabalho está organizado em três seções: a primeira sobre o desenvolvimento profissional, considerando o olhar da gestão da escola; a segunda, descrevendo a metodologia, o local, os participantes e o desenvolvimento da pesquisa; a terceira, a discussão dos dados e a análise e, por fim, as considerações finais.

\section{DESENVOLVIMENTO PROFISSIONAL DE PROFESSORES}

Para estudar sobre o desenvolvimento profissional, é preciso discutir e refletir sobre a formação inicial e continuada, compreendida como uma função formativa de construção de saberes, de saber-fazer ou do saber ser no contexto de uma profissão.

\footnotetext{
${ }^{1}$ AC - Atividade Complementar. Na Bahia é considerada como o momento em que o coordenador pedagógico e os professores se reúnem para estudar, discutir e planejar ações pedagógicas a serem desenvolvidas em sala de aula entre outras ações, bem como as demais ações da escola.
} 
A formação também pode ser entendida como um processo de desenvolvimento e de estruturação da pessoa que a vivencia com o duplo efeito de uma maturação interna de possibilidades de aprendizagem e de experiência. Pode-se ainda falar da formação como instituição, quando nos referimos à estrutura organizacional que planeja e desenvolve as atividades de formação (MARCELO GARCIA, 1999).

Nesse sentido, Imbernón (2011) explica que há similaridades entre a formação continuada e o desenvolvimento profissional. Entretanto, ao adotar a formação continuada como a única possibilidade, estaremos reduzindo o papel do desenvolvimento profissional visto que, assim, assumiríamos a formação como único meio para o professor desenvolver-se profissionalmente. Dessa forma, a formação será legítima quando contribuir para o desenvolvimento profissional do docente, melhorando o seu conhecimento da formação, da prática pedagógica, da disciplina que leciona, bem como as suas aprendizagens profissionais.

Contudo, falar de desenvolvimento profissional de professores, como algo que ultrapassa a formação, é entender as especificidades dessa profissão eo seu ambiente natural, onde tudo diz respeito a essas ações em seus detalhes. Para Imbernón (2011), há cinco linhas ou eixos de atuação que favorecem o desenvolvimento profissional, a saber: a) a reflexão prático-teórica que faz com que o professor possa, por meio da análise de sua prática, construir o conhecimento pedagógico; b) trocas de experiências entre iguais que torna possível ao professor atualizar-se em vários campos em que atua junto aos estudantes e, ainda, aumentará a comunicação e reflexão juntos aos seus pares; $c$ ) união da formação com o projeto de trabalho que é resultado de um planejamento em conjunto e não isoladamente, já que o projeto de ensino não é individual de cada professor, mas, da escola; d) formação como estímulo ao pensamento crítico, que the fará rever práticas que ocorrem no contexto de sua atuação, como hierarquia, individualismo, exclusão, intolerância entre outras; e) desenvolvimento profissional da instituição de educação e métodos de trabalho em conjunto, como meios de superar situações de isolamento profissional e individualismo.

Se considerarmos essas cinco linhas ou eixos, veremos que a formação não se esgotará na formação acadêmica, mas, alcançará o espaço da articulação da prática e ação colaborativa na escola e o desenvolvimento do pensamento crítico e reflexivo durante a trajetória profissional. (IMBERNÓN, 2011)

Nessa direção, para Marcelo Garcia (1999), existem duas linhas de desenvolvimento profissional: aquela que se ocupa de oferecer aos professores formação e maior conhecimento de suas áreas especificas, como Matemática, Linguagem, Ciências, História etc. E a outra, que entende que os professores precisam estar mergulhados em todas as etapas do processo, desde o planejamento até a análise de resultados que são ligadas ao desenvolvimento profissional.

Sendo assim, o desenvolvimento profissional do professor, quando acontece por meio de cursos de formação continuada, bem como no contexto de sua prática, tem possibilidade de proporcionar enriquecimento no âmbito moral e ético. Além disso, tais situações de formação ajudam a desenvolver um conhecimento que atribui ao professor uma capacidade de avaliar, planejar e modificar suas estratégias educativas ou 0 seu processo permanente de formação (MARCELO GARCIA, 1999).

Segundo Day (2001), o desenvolvimento profissional é algo que interfere na pessoa como um todo e não apenas no profissional. A profissão não é apenas um aspecto da vida de uma pessoa, mas, parte de algo muito maior, que é o ser humano. $O$ desenvolvimento profissional é o resultado de suas posturas frente aos desafios que afetam sua capacidade de se integrar a um projeto maior. Além disso, desenvolve suas habilidades de maneira a melhorar seus conhecimentos e práticas enquanto profissional da educação escolar.

Os motivos pelos quais se busca esse desenvolvimento são variados, porém, tudo o que acontece com o objetivo de melhorar o fazer pedagógico, pode ser entendido como ação de desenvolvimento profissional. Assim sendo, não acontece em apenas um ou outro momento, mas, vai além das práticas de formação, está presente nas ações do dia a dia do professor. Pode ou não se refletir no salário, pode ou não estar atrelado a mais formação acadêmica, mas, sobretudo, pode ser entendido como estímulo e amadurecimento profissional o que, certamente, promove reflexão (IMBERNON, 2011).

Convencionalmente, o professor é aquele que detém algum tipo de conhecimento próprio 
da profissão. Trata-se no âmbito da Educação, esse conhecimento como conteúdo. Segundo Shulman (1987), podemos, então, dizer que esse professor se transforma de maneira tal, quando compreende o contexto e conteúdos (teorias e práticas) que ainda não compreendia.

Para Shulman (1987), essa transformação no conhecimento do professor é o início das reflexões sobre o ensino, pois, muito embora, seja do aluno a tarefa do aprendizado, este começa quando o professor entende o que deve ensinar. Cabe, ainda, ao docente saber como deve ensinar e quais estratégias usar para que o discente alcance seu aprendizado e o ensino se realize como algo além de uma simples melhoria da compreensão. $O$ ensino e a aprendizagem precisam acontecer para transformação das pessoas e, certamente, da sociedade.

Nesse sentido, esse conjunto de conhecimentos, como entende Shulman (1987), contribui ao desenvolvimento profissional de professores. Para Marcelo Garcia (1999), o desenvolvimento profissional tem uma conotação de aprofundamento e continuidade dos estudos, superando a justaposição entre a formação inicial e a continuada.

As atividades de desenvolvimento não afetam apenas o professor, mas àqueles que têm alguma responsabilidade ou implicação no desenvolvimento profissional e a pessoa do professor na escola. Não acontece de forma isolada, ocorre também, no contexto em que o mesmo está mergulhado.

Day (2001) apresenta uma definição sobre o desenvolvimento profissional, não como sendo uma única coisa ou um único aspecto, mas, mostra uma visão holística desse desenvolvimento, como algo que interfere no ser/estar/fazer/aprender/ensinar do professor. Entende-o como a soma dos desafios no ensino e aprendizagem que mexem com sua capacidade para se empenhar profissionalmente e desenvolver suas habilidades, de forma a melhorar a educação e os resultados escolares das crianças e dos jovens.

O sentido de desenvolvimento profissional dos professores depende da história de suas vidas profissionais e pessoais, de políticas públicas e contextos escolares nos quais realizam suas atividades docentes. Considerando essas políticas como oportunidades oferecidas aos professores em atividades formais e informais, que o ajudará no revisar, renovar, refletir e refazer seus pensamentos e ações e, sobretudo, seu compromisso profissional (DAY, 2001).

Outro aspecto do desenvolvimento profissional é a organização curricular que, muitas vezes, está mais ligada a decisões de governo e que interfere na prática dos professores e não, raramente, está ligada aos conteúdos curriculares (MARCELO GARCIA, 1999). Logo, o processo de construção de um projeto curricular em que o professor participe ativamente para torná-lo adequado àquela comunidade escolar, é também processo de desenvolvimento profissional do professor.

Por isso, sempre foi necessário adquirir qualificação, formação, para ser professor. Todavia, apenas a formação não é suficiente, pois é necessário repensar a organização do ensino, o apoio da gestão da escola, os materiais que são disponibilizados, atualização dos conhecimentos, tanto do conteúdo quanto pedagógico. Além de tudo isso, tendo em vista a melhoria do seu ensino, o professor deve ser comprometido em questionar, ter destreza para analisar seu próprio ensino e estar disposto a permitir que outros professores analisem seu ensino (DAY, 2001).

\subsection{A GESTÃO E O DESENVOLVIMENTO PROFISSIONAL NA ESCOLA}

Segundo Day (2001), os gestores afetam e são afetados pela cultura de seu grupo, instituição ou rede de ensino, pois, lhes cabe o papel de gerir tantos as metas racionais, como as metas não-racionais nas suas interações diárias com os colegas, que influenciarão no futuro imediato da escola e nas situações presentes, empenhando-se na partilha de ideias e pacificação das linhas de pensamento pedagógico, político e social - e na gestão das mudanças - educacionais, técnicas e administrativas - que venham a ocorrer no âmbito da escola.

A responsabilidade e influência dos gestores na cultura escolar vão além do organizacional, visto que influencia na visão e no entendimento que seus pares terão a respeito de seu próprio desenvolvimento profissional, atuando assim, em favor da criação de uma cultura de aprendizagem e de mudança na escola, não só ajudando a controlar comportamentos, mas ajudando a criar consciência do papel de cada um na instituição, por proporcionar situações para novos hábitos e conhecimentos, bem como o desenvolvimento dos professores na escola (DAY, 2001). 
Os diretores dos estabelecimentos de ensino devem ser líderes que articulam uma visão global, que promovem a partilha de ideias e se empenham numa planificação evolutiva, lidando com a cultura, o desenvolvimento e as mudanças (DAY, 2001). Assim, há quatro tipos de lideranças que podem ser desenvolvidas por gestores escolares, tais como:

Liderança normativo-instrumental é aquela em que o gestor (diretor) das escolas "trabalha, 'através' dos professores para articular as suas (dos diretores) visões, metas e expectativas, por forma a influenciá-los a 'comprarem' o seu programa de trabalho" (DAY, 2001 , p. 136). Uma estratégia eficaz, entretanto, os professores, nem sempre, identificam suas necessidades e objetivos, condição que não contribui à construção da autonomia dos professores. Os diretores assumem a função de motivar os professores para implementar os objetivos de instituições externas, não os envolvendo em reflexão sobre o seu trabalho na escola. Tais estratégias mantém o professor como aquele que tem um papel de subordinado no desenvolvimento de suas ações (DAY, 2001).

Liderança facilitadora é aquela que o gestor exerce, criando atitudes tais como: demonstração de confiança nos professores, desenvolvimento de estruturas de gestão partilhada com os colegas, encorajamento das participações individuais, estímulo à autonomia dos professores, encorajamento à inovação e à criatividade dos professores, reconhecimento de suas atitudes diante das dificuldades do dia a dia e apoiar seus liderados.

Liderança emancipadora é aquela que quando exercida, leva a ultrapassar as características da liderança facilitadora, por buscar soluções para amenizar as diferenças de poder e construir um ambiente mais justo e democrático, fazendo equiparar os "poderes" dos atores na escola, pois, em cada caso, é definida pela própria comunidade escolar, pautada nos próprios valores éticos e no bem comum.

Outro tipo de liderança, identificado por Day (2001), a partir de estudos realizados na Inglaterra, é a Liderança libertadora. Essa é uma das formas de liderança que melhor se adequa às atuais e futuras gerações de gestores, pois mais do que emancipar as pessoas que lideram, esse tipo de gestor, estimula a emancipação que já existe em cada um desses, na medida em que acredita na própria capacidade e na capacidade de cada pessoa que lidera; empolga seus liderados e a si próprio e, ainda, reflete esse entusiasmo em suas ações, protege e apoia os seus.

$\mathrm{Na}$ liderança libertadora, os gestores ajudam os professores a tornarem-se pessoas de sucesso, reconhecendo e estimulando seu potencial por meio de orientação, combinando e distribuindo tarefas e respeito às posturas dos colegas. Considerando sempre uma abordagem pessoal com cada pessoa, sem padrões impessoais. Dá liberdade às capacidades de cada um, encoraja seus liderados a assumirem responsabilidades na organização da escola, tornando ambientes que antes eram hierárquicos, em ambientes democráticos.

Day (2001), apoiado nos estudos apresentados por Tampoe (1998), enumera dez características dos líderes libertadores, as quais listamos a seguir:

1 - acreditam, de forma convicta, nas próprias capacidades e nas capacidades das outras pessoas e pretendem libertar este poder latente nos outros e em si mesmos;

2 - entusiasmam os seus seguidores e o seu entusiasmo reflete-se em tudo o que fazem;

3 - agem como protetores dos outros, isto é, apoiam os seus seguidores contra os ataques de interesses exteriores;

4 - através de um processo de orientação e monitorização,

desenvolvem a autoestima dos seus seguidores que apresentam um potencial para se tornarem pessoas de sucesso efetivo ou pessoas que dão o seu contributo profissional;

5 - administram usando uma combinação eficaz de direção, delegação e auscultação;

6 - aumentam o valor de seus seguidores, assegurando que estejam em harmonia com o seu ambiente e a produzir resultados eficazes; 
7 - respeitam os outros e acreditam que eles, desde que lhes sejam dadas oportunidades, poderão contribuir para o sucesso da organização, pela sua própria conviç̧ão e impulsos interiores;

8 - personalizam sua abordagem de liderança, em vez de generalizarem, na medida em que não procuram ou usam a abordagem da única e "melhor" prática, mas, preferem criar uma relação de empatia, em que o comportamento de líder se adequa ás necessidades dos que são orientados;

9 - libertam a capacidade de autoliderança latente dos seus seguidores, ou seja, agem de forma a encorajar os seus seguidores a responsabilizarem-se pelo seu ambiente e a assumir a responsabilidade, prestando contas pelas suas próprias ações;

10 - democratizam os ambientes de trabalho hierárquicos, usando as estruturas, processos e procedimentos para fortalecer e capacitar os seguidores em vez de os controlar (DAY, 2001, p. 138-139).

Para Day (2001), nesse tipo de liderança, é necessário que a equipe da escola se empenhe no desenvolvimento profissional contínuo dos professores, dos auxiliares, enfim, de todos, para conseguir resolver o assim chamado problema de liderança, (termo usado pelo autor) que vem a ser o desafio de envolver todos na ideia ou projeto desse gestor de somar esforços para superar obstáculos, enquanto aumentam a capacidade da própria equipe em enfrentar desafios que surgirão durante 0 seu desenvolvimento. A coordenação e a direção são as instâncias da escola que compõem a gestão, desenvolvendo ações de:

$$
\begin{array}{llr}
\text { a) a } & \text { execução } \\
\text { coordenada e integral de }
\end{array}
$$

atividades dos setores e indivíduos da escola, conforme decisões coletivas anteriormente tomadas;

b) $0 \quad$ processo participativo de tomadas de decisões, atentando ao mesmo tempo, para que estas se convertam em medidas concretas efetivamente cumpridas pelo setor ou pelas pessoas em cujo trabalho são aplicadas

c) a articulação das relações interpessoais na escola e no âmbito em que o dirigente desempenha suas funções (LIBÂNEO; OLIVEIRA; TOSCHI, 2012, p. 475).

Assim, as mudanças nas ações do gestor o têm afastado cada vez mais das ações realizadas e dos fazeres da sala da aula. Dessa forma, o gestor deve conhecer sua equipe e se deixar conhecer por ela, bem como entender o tempo, o funcionamento e os impedimentos de sua função (DAY, 2001).

Considerando os estudos apresentados por Day (2001), referentes à gestão da escola, há uma ênfase na gestão democrática, participativa e libertadora, numa perspectiva de emancipação e autonomia das pessoas em suas diferentes funções na escola.

\subsubsection{O COORDENADOR E O DESENVOLVIMENTO PROFISSIONAL DE PROFESSORES NA ESCOLA}

Nos Estados Unidos, na década de 1980 e, no Brasil, desde início da década de 1990, têm surgido estudos que passaram a entender a sala de aula e a escola como espaço para a pesquisa. Nesse contexto, há a presença de um profissional, o coordenador pedagógico, que articula as ações pedagógicas na escola, que constrói sua trajetória profissional no contexto de aprendizagens e tensões entre aquilo que ele é e aquilo que parece ser para os outros, entre o que decorre das estruturas legais, da estrutura escolar e de sua formação (inicial e continuada) com suas experiências atuais e passadas (PLACCO; SOUZA; ALMEIDA, 2013).

Para Placco, Souza e Almeida (2013), o termo, utilizado para a função que aqui chamamos de coordenador pedagógico, pode 
colaborar com a identificação da sua função na escola, interferindo diretamente, no seu modo de agir e se colocar nesse ambiente.

Como estamos tratando de escolas do Ensino Fundamental anos iniciais, a postura do coordenador pedagógico irá depender da legislação no município, que, em geral, atribui ao coordenador pedagógico funções como liderança do Projeto Pedagógico, avaliação de desempenho da escola e dos alunos, organização de relatórios para os órgãos gestores, diálogos com os pais e comunidade, gestão de material didático e atividades ligadas à formação dos professores etc. (PLACCO; SOUZA; ALMEIDA, 2013).

Para Placco, Souza e Almeida (2013), entre as atividades desenvolvidas, algumas são formativas, outras são, potencialmente, formativas e outras, ainda, não são referentes ao papel formativo, as quais, muitas vezes, desviam o coordenador do seu papel central no funcionamento pedagógico da escola, atribuindoIhe uma variedade muito grande de funções, o que é um prejuízo, por conta da relevância do seu trabalho junto aos professores.

É na escola que o professor continua a aprender e a se desenvolver na profissão, na construção de conhecimentos da disciplina, pedagógicos, curriculares, sobre os alunos e os fins e propósitos da educação (SHULMAN, 2014). É no dia a dia, atendendo a demandas vindas dos professores, que o coordenador pedagógico desenvolve e constrói uma identidade ao longo do tempo em que se desencadeia uma espécie de adesão desses profissionais ao seu fazer pedagógico.

Existem, segundo Placco, Souza e Almeida (2013), cinco tipos de visões que os professores têm em relação ao coordenador pedagógico e seu trabalho desenvolvido na escola:

1 - O gestor: quando o professor vê o coordenador pedagógico dessa maneira, ele tende a conceber que na presença ou ausência do diretor, o coordenador é uma das pessoas que gerencia a escola, logo o procura para resolver questões referentes a: rotinas dos professores, tarefas administrativas, horários escolaresou atender a emergências.

2 - O elo entre a escola e o sistema de educação (municipal ou estadual). Nessa visão, o professor entende que o coordenador é responsável por avaliações externas, pesquisas, relatórios e elaboração e desenvolvimento de projetos advindos dos órgãosgovernamentais.
3 - O solucionador de problemas: é um resolvedor de conflitos (termo utilizado pelas autoras) entre o aluno e o professor, pais e professores, pais e gestão e uma gama de outras questões que permeiam o ambiente da escola.

4 - 0 formador de professores: responsável por buscar formação para seus professores, ajudá-los a elaborar suas aulas, planejar conteúdos, fundamentos teóricos sobre ensino, aprendizagem e políticas educacionais.

Assim, cuidar da formação continuada dos professores, é a principal atribuição dos coordenadores pedagógicos, porém, segundo Placco, Souza e Almeida (2013), fica diluída em meio a uma gama de atribuições que sempre recaem sobre o coordenador, muitas vezes, por ausências ou impedimentos dos gestores o que, em alguns casos, chegam a causar angústias e desconfortos, tirando-lhe a oportunidade de participar mais ativa e efetivamente da formação de seus coordenados.

5 - O parceiro: é como um ombro amigo, uma âncora e bússola ao mesmo tempo, ele existe para orientar e ajudar a assimilar a realidade, para ouvir as angústias e animar na busca por novos conhecimentos.

Coordenadores que são vistos pelos professores de formas variadas assumem esses diferentes papéis e tendo, por sua vez, reclamações diferentes a respeito do comportamento do professor. Por exemplo, quando assume o papel de gestor, acaba tendo mais clareza em acompanhar atitudes do professor como assiduidade, pontualidade, empenho em tarefas designadas, receptividade dos professores em relação às solicitações da gestão, maior dificuldade com professores que faltam muito etc. (PLACCO; SOUZA; ALMEIDA, 2013).

Para as autoras, é frequente a ideia de que o principal papel do coordenador pedagógico é fomentar e incentivar a formação continuada dos professores, na escola e fora dela, desenvolvendo relações humanas, afetivas e sociais na construção do seu trabalho, estimulando a participação destes em cursos, seminários e congressos. Ressaltamos que para desempenhar tais funções o coordenador pedagógico deve ter uma formação específica

Conforme Placco, Souza e Almeida (2013), ao coordenador pedagógico cabem ações como sugerir ao professor leituras, cursos, orientações técnicas ou promover estudos em conjunto, o que está ligado ao conhecimento da 
matéria de ensino, mobilizado pelo professor quando planeja e ensina. É tarefa do coordenador pedagógico promover discussões sobre técnicas de gestão da turma ou de teorias pedagógicas, que estão ligadas ao conhecimento pedagógico e, ainda, a partir de conversas e trocas de experiências com os colegas, promover com o professor discussão sobre o conhecimento pedagógico do conteúdo.

Para Tozetto e Kailer (2019) é, ainda, na universidade, durante a formação inicial, que o pedagogo começa a construir a função do professor ou coordenador e, assim sendo, pode o curso the atribuir uma visão mais ampla que the permita se imaginar em ambas as funções.

Das experiências em sala de aula, o coordenador traz possibilidade de falar com conhecimento de causa com seus pares, pode relatar situações que as teorias não poderiam mostrar. Porém, não basta a experiência, é preciso construir saberes que envolvam teorias de currículo, organização sistemática da escola, políticas públicas entre outros saberes que ultrapassam a experiência. Há, ainda, saberes que são socializados com os colegas coordenadores e gestores. A coordenação não é uma atividade neutra, é orientada a cumprir políticas públicas e isso pode levar a transformações ou à manutenção do status quo (TOZETTO; KAILER, 2019). Ademais, a formação inicial deve deixar claro ao futuro coordenador pedagógico elementos que contribuam para entender sua posição na escola e os limites do trabalho pedagógico, pois é comum haver situação em que o coordenador assume papeis dos mais diversos na escola. Situação, muitas vezes, provocada pela precariedade nas condições de funcionamento das unidades, assim como lugar privilegiado da formação desse profissional (TOZETTO; KAILER, 2019).

Para Tozetto e Kailer (2019), o coordenador pedagógico é fio condutor da formação continuada dos professores na escola, porém, essa tarefa está sendo dificultada, às vezes, até no simples ato de conduzir reuniões pedagógicas, pela quantidade de atribuições que lhe cabe. Assim, acaba não podendo agregar ao grupo de professores os conhecimentos, muitas vezes, adquiridos por cada um isoladamente, em que, além disso, ele poderia por meio de referenciais teóricos, conectar os conteúdos que o professor estudou com o que é vivenciado no seu fazer pedagógico.
Nessa condição, a quantidade de eventos imprevisíveis da escola acaba que tomando tempo do coordenador, emergindo também saberes dos quais ele mobiliza para lidar com os pais de alunos, visitantes e as pessoas da comunidade escolar, o que é reflexo de gestão participativa (LIBÂNEO, 2013). Então, serão necessários saberes que devem ser oportunizados ao coordenador ainda na sua formação inicial, pois, segundo Tozetto e Kailer (2019) são basilares para sua futura atuação.

As ações do coordenador pedagógico não estão desvinculadas das atividades docentes. Assim, como as ações do professor, as do coordenador não são dotadas de neutralidade política. A escola é sempre permeada de concepções históricas, políticas, sociais, culturais e econômicas e, assim sendo, é claro que essa história e meio social terão reflexos nas ações do coordenador (TOZETTO; KAILER, 2019).

\section{PERCURSO METODOLÓGICO}

Uma pesquisa que está sendo desenvolvida em parceria com universidades localizadas nas regiões Nordeste e Sudeste (UFPE, UFC, UECE, UFCA, UFRN, UNICAMP, UNEB, UNINOVE, IFRN) e a Universidade de Lisboa, apresenta abordagem qualitativa que, de acordo Lüdke e André (1986, p. 11) "tem o ambiente natural como fonte direta de dados e o pesquisador como seu principal instrumento". Este ambiente é a escola.

Nesta pesquisa a nossa preocupação é com o processo (LÜDKE; ANDRÉ, 1986), visto que temos como objeto de estudo o desenvolvimento profissional do professor, na escola, no olhar do diretor e do coordenador pedagógico.

A pesquisa foi realizada em uma escola pública que oferta os anos iniciais do Ensino Fundamental, funciona em parceria com uma ONG, atende a crianças e jovens de um bairro popular, sendo localizada em uma cidade da região Sul da Bahia.

As participantes da pesquisa foram a diretora e a coordenadora pedagógica da área de Matemática da escola. As participantes assinaram o Termo de Consentimento Livre e Esclarecido (TCLE) e foram identificadas com nomes fictícios, para preservar suas identidades.

Nomeamos a diretora como Tália. Ela é formada em Pedagogia com especialização em Gestão Educacional e Psicologia Social, professora há 33 anos, está há 14 na diretoria da escola na qual realizamos a pesquisa. A 
coordenadora a quem chamaremos de Ceres é formada em Pedagogia com especialização em Ensino Superior e Educação Infantil, com 23 anos de experiência educacional atuando em escolas públicas, há treze anos está na coordenação pedagógica, sendo os quatro últimos, na instituição da pesquisa.

Para obtenção dos dados foram realizadas entrevistas com a diretora e a coordenadora pedagógica da área de Matemática, com o objetivo de "recolher dados descritivos na linguagem do próprio sujeito, permitindo ao investigador desenvolver intuitivamente uma ideia sobre a maneira como os sujeitos interpretam aspectos do mundo" (BOGDAN; BIKLEN, 1994, p. 134), e interferem de forma direta na atuação e desenvolvimento profissional dos professores.

Dessas entrevistas, colhemos informações que nos ajudaram a entender como atuam, o quê há de intencionalidade na prática pedagógica e como seus depoimentos e atuações são recebidas e socializadas com os professores.

Para análise dos dados, elegemos como categoria de análise 0 desenvolvimento profissional de professores na escola e para analisa-la, recorremos às práticas discursivas entendidas como uma "prática social, dialógica" (SPINK; MEDRADO, 2013, p. 22) para "explicação dos processos pelos quais as pessoas descrevem, explicam ou contabilizam o mundo no qual vivem, incluindo em si mesmas" (SPINK; MENEGON, 2013, p. 54). Durante a pesquisa, a descrição e explicação feitas por Tália e Ceres forneceram pistas para compreender $\mathrm{O}$ movimento da gestão no desenvolvimento profissional dos professores que lecionam Matemática, numa tentativa de "ressignificação da relação sujeito e objeto, que pressupõe a desfamiliarização com a ideia cristalizada de dualidade" (SPINK; MENEGON, 2013, p. 55).

Com esse método de análise, o pesquisador e as participantes da pesquisa são considerados colaboradores de um novo conhecimento. Assim, o diálogo entre os autores que estudam o desenvolvimento profissional e os dados da pesquisa constituíram-se como corpus desse novo conhecimento para compreender o seu objeto na visão da gestão da escola.

\section{DESENVOLVIMENTO PROFISSIONAL NA VISÃO DA GESTÃO DA ESCOLA}

Com o propósito de responder a indagação proposta neste artigo, fez-se necessário conhecer de que forma as participantes pensavam sobre o desenvolvimento profissional. Para tanto, elaboramos as entrevistas com o objetivo de construir esse novo conhecimento. Qual o movimento que a gestão da escola propõe para o desenvolvimento profissional de professores na escola? Esse é um questionamento que só poderia responder quem tem está inserido no contexto da escola. Sobre o desenvolvimento profissional, Tália nos diz:

Olha, eu acredito, por desenvolvimento

profissional, as questões inerentes à formação inicial do sujeito e depois os cursos de aperfeiçoamento e os momentos de estudo do pessoal, que o profissional busca para poder melhor atuar na área em que ele está, e fazer as intervenções necessárias.

A partir de um momento de estudos pessoais e grupais, a partir da participação de cursos, seminários, simpósios, leituras, acredito que a partir desses elementos (Tália, Entrevista).

Bom, eu penso que o desenvolvimento profissional do professor, ele deve acontecer em serviço, para que o professor possa estar relacionando a sua prática diária, com a formação, para que ele possa estar levando as situações que ele vivencia dúvidas, para essa formação, para que ele possa estar continuamente, refletindo também sua própria prática (Ceres, Entrevista).

O pensamento de Tália sobre 0 desenvolvimento profissional se aproxima dos estudos de Marcelo Garcia (1999), quando declara que os conhecimentos construídos na formação inicial aproximam o professor do mundo em que ele irá atuar, mas, que o mesmo 
terá no contexto de sua vida profissional, outros momentos de reflexão sobre a profissão e enriquecimento teórico, como os momentos de estudos, participação em seminários, cursos, leituras etc.

Imbernón (2011) também corrobora com essa visão, e acrescenta que não devemos inferir o Desenvolvimento Profissional unicamente como resultado de seu enriquecimento teórico pedagógico. $\mathrm{O}$ resultado desse processo está ligado as situações vivenciadas nesse universo, isto é, quando "busca para poder melhor atuar na área em que ele está" (Tália, Entrevista).

O desenvolver-se profissionalmente está relacionado às possibilidades que o professor tem para aprender sobre o ensino das disciplinas e disposição para se aprofundar no conhecimento específico da área de atuação, no nosso caso, a Matemática, com o apoio da direção. Além disso, é função do diretor criar condições para o aprender mais, estudar sempre. Ele é um formador. Essa é uma das fontes do conhecimento do professor (SHULMAN, 1987) e que são enfatizadas na visão de Tália e Ceres.

Eu acredito que, garantir essa formação continuada dentro do espaço escolar, dentro da carga horária para esse fim, não desmerecer esse momento, [...], mas, dar essa a importância devida, incentivar também o seu professor à buscar a leitura e fazer relatos de experiências, buscar outros relatos para partilhar com o grupo, para que ele cresça. Incentivar também o curso e na medida do possível, incentivar até participar de cursos fora [escola], que a gente sabe que na docência efetivamente com um professor que está na docência, com 40 horas, ou no município onde não existe reserva técnica, essa tarefa é muito complexa de se ajustar, da realidade, que você fica, ou o professor participando da formação, ou aluno na escola, e aí, como equilibrar essas duas realidades?

(Tália,

Entrevista)

[...] o papel do gestor, na formação profissional do professor é de grande importância, "né"? Porque ele é quem vai estar permitindo, digamos assim, que as coisas realmente aconteçam, ele pode estar articulando o grupo "né" organizando os tempos na escola para isso e também até participando. Uma maneira também de incentivar aos professores. Então, é de grande importância, papel do diretor na formação em serviço. Ele também é um formador, dentro da escola, então, eu acho ele precisa chegar junto com toda a equipe (Ceres, Entrevista, grifo nosso).

Como se pode observar, Tália, ao falar de tempo para a formação, menciona existência de reserva técnica, que foi instituída no Parecer do Conselho Municipal de Educação - PARECER CME/CLN № 001/2017 que reorganiza a proposta pedagógica da Rede Municipal de Ensino de Ilhéus. Em relação ao papel do diretor nesse desenvolvimento profissional dos professores, Ceres, também, concorda que este deve ser um incentivador, concordando com Day (2001) quando diz que os diretores são líderes e têm a função de articulador das ações administrativas, formativas e pedagógicas na escola.

Enquanto organizam o tempo do docente na escola, de forma que ele tenha momentos propícios para refletir suas práticas ou buscar novos conhecimentos, a gestão e a coordenação colaboram para o desenvolvimento profissional e enriquecimento teórico e prático deste, visto que as pessoas que fazem parte da gestão são formadoras na escola. Acompanhamos ações na escola que indicam que o desenvolvimento profissional ultrapassa as práticas de formação e está presente nas ações do dia a dia do professor, como por exemplo, na elaboração e discussão de sequências de ensino e reflexão da prática pedagógica. Situações que podem ser vistas como estímulo ao crescimento 
pessoal e profissional e à mudança nas relações de trabalho por proporcionar um novo olhar sobre as mesmas (IMBERNÓN, 2011).

Assim, há dois movimentos nesse contexto que ajudam os gestores na organização das ações na escola e podem influenciar o desenvolvimento profissional dos professores: o Projeto Político Pedagógico (PPP) da escola e a cultura da escola. Ambos têm influência na carreira e no trabalho do professor, seja pela previsão (escrita, textual, oficializado no PPP) ou pelo costume, isto é, pelo ambiente e relações que cria e que está diretamente ligado ao trabalho do professor e a comunidade, e as relações estabelecidas com as famílias - pais e alunos. As entrevistadas relataram que o PPP sugere situações de desenvolvimento profissional:

[...] lá nós temos, não diria um capítulo, mas uma parte dentro Projeto Político Pedagógico, e o município vem também tentando, dentro da sua política educacional já estar garantindo algumas questões, a questão da formação continuada do professor, e vem promovendo os cursos de atualização da prática pedagógica, das mudanças... Os estudos necessários através da BNCC, através das matrizes curriculares desse novo currículo que se está querendo implementar, dos direitos de aprendizagem. Então, vem atualizando 0 professor de todas essas questões que ele precisa estar atualizado para exercer a sua prática docente (Tália, Entrevista).

Essa questão, assim, ela é um dos pontos de grande relevância do Projeto Político Pedagógico, mesmo porque, o professor, é um profissional que é quem conduz, na verdade, na prática mesmo, toda aprendizagem, todo o conhecimento que é construído pela criança. Claro que todos os outros profissionais

(coordenador, orientador e direção), cada um tem um papel, com certeza, mas o professor precisa sim perceber que a escola tem essa questão documentada que leva a sério, que faz parte da nossa proposta, mesmo de formação do professor para que a nossa educação seja cada vez de maior qualidade (Ceres, Entrevista).

Tália e Ceres relatam que o PPP da escola indica que o professor vem participando de situações para atualizar-se e estão sempre em busca de mais conhecimento. Tais respostas confirmam o que Day (2001) diz a respeito do gestor que exerce a liderança do tipo libertadora, pois, nesse tipo de liderança, é necessário que a equipe e estrutura da escola devem estar empenhadas em garantir $o$ processo de desenvolvimento profissional dos professores.

Pensar a estrutura da escola, entre outras coisas, está a possibilidade de reconhecer que o PPP é o documento para organizar o tempo do professor na escola, de forma que ele possa participar de eventos de formação continuada. Também podemos listar neste aspecto, a utilização do trabalho do gestor e coordenador pedagógico como facilitadores do acesso dos professores a essas oportunidades. No caso específico da escola, tem as ações da ONG, tais como: "formação em serviço ou a formação que a escola, juntamente com a Fundação programa para acontecer ou a formação estudo, oferecido pelo grupo colaborativo, como todos esses momentos acontecem dentro da carga horária do professor" (Ceres, Entrevista).

A cultura da escola é um item que aparece como influente no desenvolvimento profissional do docente. Para Day (2001) e Libâneo (2013) a cultura da escola interfere diretamente no contexto de trabalho do professor, logo tem influência no desenvolvimento. Essa cultura se expressa, por exemplo, na disposição dos professores em participar de atividades que levam ao que Day (2001) chama de cultura de aprendizagem e de 
mudança na escola. Situações que foram mencionadas nos relatos de Tália e Ceres sobre as dinâmicas e o envolvimento dos professores em situações de desenvolvimento profissional:

[...] os professores
participam daquele
programa federal, do ciclo
dois do Pacto, Pacto pela
Educação, que são, todos
os professores se
encontram uma vez por
mês, para estudos,
discussões e dinâmicas,
isso já vem acontecendo
há alguns anos, e os
professores dos anos
iniciais eles têm um
momento em que se
encontram da dinâmica do
Pacto, que é mais para o
Ciclo de Alfabetização, que
são os três primeiros anos.
Mas, eles estão tendo
encontros mensais para
reflexão da prática e
estudos também (Tália,
Entrevista).

Veja só, como a formação em serviço ou a formação que a escola, juntamente com a Fundação programa para acontecer ou a formação estudo, oferecido pelo grupo colaborativo, como todos esses momentos acontecem dentro da carga horária do professor, ele está envolvido sim, dessa maneira, ele está envolvido, porém, a gente sabe, nós percebemos durante o processo que nem todos estão abertos para, muitos ainda têm assim, postura mais fechada, não querem aceitar tanto, algumas formações. Mas, assim o que nós fazemos para convencer, é justamente o diálogo, é a conversa, é o dizer que é importante e não deixar de acontecer porque a maioria participa, a grande maioria se envolve, então, a gente não tem como deixar aquele não participar. Então, ele participa, às vezes não está, assim, muito aberto para, mas temos observado que até esses, que em muitos momentos não estão tão abertos para, é... Tem tido um avanço, tem tido uma melhora, eles realizam, eles fazem, eles buscam, mas o que nós, enquanto equipe gestora, procuramos e almejamos é que toda a equipe deseje essa formação. Então, é algo que a gente vai conquistando no dia a dia e com a nossa prática, também, com a nossa postura de valorização do profissional de valorização da formação com os resultados que a gente obtém, por percebermos que determinada formação por um período, tem nos dado o maior conhecimento para lidar com as questões pedagógicas. Então, tudo isso é., mostra para o professor que esse deve ser o caminho. Então, a gente está na batalha (Ceres, Entrevista).

Para Ceres, o diálogo e a conversa são alternativas para convencer o professor de que a formação é importante para a construção de conhecimento, bem como as vantagens financeiras. Essas vantagens estão estabelecidas no plano de carreira do município ${ }^{2}$ que estabelece um percentual a ser acrescentado ao

\footnotetext{
${ }^{2}$ Art. 41. A Gratificação de Estímulo ao aperfeiçoamento profissional será incidente sobre o vencimento ousalário básico atribuído ao cargo ocupado pelo beneficiário, e será equivalente a:

I - 5\% (cinco por cento) aos portadores de certificado de curso com duração mínima de 80 (oitenta) e máxima de 119 (cento e dezenove) horas;

II - $10 \%$ (dez por cento) aos portadores de certificado de curso com duração mínima de 120 (cento e

vinte) e máxima de 359 (trezentos e cinquenta e nove) horas;

III - 15\% (quinze por cento) aos portadores de certificado de curso com duração mínima a partir de 360

(trezentos e sessenta) horas. Parágrafo único - É permitida a percepção cumulativa dos percentuais previstos neste artigo, desde que decorrentes de cursos diferentes e limitado ao percentual máximo de 50\% (cinquenta por cento) (ILHEUS, 2008, p. 13).
} 
salário base do professor, à medida que esse participa de cursos de formação continuada.

Ao gestor cabe gerenciar as metas da escola, nas interações diárias com os colegas, negociando, incentivando e pacificando pensamentos, sem perder de vista que ele influencia e é influenciado pela cultura da mesma (DAY, 2001). Direção e coordenação são, de acordo com Libâneo, Oliveira e Toschi (2012), as instâncias que compõem a gestão da escola, são corresponsáveis por mobilizar os docentes e técnicos para participarem de atividades de desenvolvimento profissional.

$\mathrm{Na}$ fala de Ceres fica retratada duas das cincos visões que o professor pode ter em relação ao coordenador pedagógico: o formador e o parceiro (PLACCO; SOUZA; ALMEIDA, 2013). Há duas atitudes de Ceres que revelam essas modalidades, o incentivo ao professor para que participe das formações e a participação dela nessas formações.

\subsection{DESENVOLVIMENTO PROFISSIONAL NA VISÃO DO COORDENADOR PEDAGÓGICO}

O coordenador pedagógico é fio condutor para a formação do professor na escola (TOZETTO; KAILER, 2019) e quando participa das oportunidades de formação continuada, há a possibilidade de ajudar os professores a ligar o que ele e o professor estudaram suas práticas docentes. Para que pudessem participar dessas formações, então o que víamos era a diretora assumido papéis de incentivadora e protetora, organizando com Ceres, as tarefas e eventos (previsíveis e imprevisíveis) para que não deixasse de estar presente.

Ceres declara que ao participar da formação sente-se mais à vontade parra participar dos planejamentos com os professores, em relação às aulas de Matemática: [...] "eu percebi em mim mesma, é uma compreensão melhor, principalmente dessas questões, de estatísticas, que é o que nesse momento, que eu que estou acompanhando o grupo" [...]. Segundo Ceres essa participação ainda não resolveu tudo: "mas, o conhecimento que eu tenho, dá para manter um diálogo com o professor (sobre conceitos matemáticos) de maneira que a gente discuta as questões, discuta as dúvidas" (Ceres, Entrevista).

Ao participar das situações de formação na escola, Ceres se familiariza com o conteúdo da formação e como os professores estão participando e aprendendo 'novas' maneiras de ensinar e aprender. Tal condição facilita o diálogo, o planejamento e as intervenções, que necessita fazer enquanto coordenadora. Para Ceres, estar alinhada com os conhecimentos do professor possibilita condições para ajudar este no desenvolvimento de suas ações em sua prática na sala de aula, e nos relata uma situação que aconteceu na escola, em relação ao conteúdo de Matemática (estatística):

[...], estamos estudando as questões de estatísticas juntos a partir da formação que oferecida pelo grupo colaborativo, [...], sentimos também dificuldade em algumas coisas que dizem respeito ao conhecimento de estatística, quando nós observamos que há uma dificuldade por parte de alguns professores. $\mathrm{O}$ que a gente busca é sentar com esse professor, ouvir, entender o que está sendo dificuldade para ele aplicar e aí tentamos orientar dentro do que conhecemos também. Discutimos aquela questão, lemos alguma coisa, perguntamos a um professor que a gente acredita que ele tem um conhecimento maior daquelas questões que tão sendo realizadas, e aí a gente vai se construindo dessa maneira. Nós tivemos uma professora mesmo, no ano retrasado, que ela estava com dificuldade de fazer gráfico, um gráfico de dupla entrada e para explicar a gente conversou, orientou, mas ela só entendeu, quando foi realizado com ela na prática. [...] ela conseguiu internalizar

\section{$\mathrm{e}$} compreender, como é que ela poderia também está fazendo isso com os alunos. Então, a gente tenta lançar mão assim das estratégias possíveis, sempre valorizando 
também o conhecimento dos professores que estão com a gente, que estão estudando conosco e na formação em serviço também com a gente (Ceres, Entrevista).

A primeira atitude da coordenadora em relação às dificuldades do docente é estudar junto, o que mostra uma atitude de parceria, quando fala em buscar com outro professor que tenha uma facilidade maior, está na realidade articulando discussões entre eles.

Em seus escritos, Marcelo Garcia (1999) sugere que a articulação entre a formação de professores em relação aos conteúdos acadêmicos e disciplinares e a formação pedagógica dos professores é o princípio que lida diretamente como o 'conhecimento pedagógico do conteúdo', estudado por Shulman (1986; 1987).

Ceres valoriza a troca de experiências e conhecimentos (da Matemática e pedagógico) entre os professores, buscando mais conhecimento, o que integra duas atitudes, a de valorização e incentivo ao estudo e a de oferecer suporte aos professores que enfrentam dificuldades em relação ao conteúdo especifico (estatística) e o conhecimento pedagógico.

Ao mencionar o caso da docente que tinha dificuldades para ensinar o conteúdo gráficos, Ceres fala do bom resultado da integração e colaboração de um colega: "Pedimos ajuda a um colega que também trabalhava com a mesma fase, aí, quando ele fez com ela, ela conseguiu internalizar e compreender, como é que ela poderia também está fazendo isso com os alunos" (Ceres, Entrevista).

A ação traduz o que diz André (2016), quando declara que a melhoria da prática não deve ser encarada como uma atividade individual e que o contexto da escola é o lugar da integração da teoria com a prática, e que todos devem participar dessa reflexão. Corroborando essa visão, Schön (2000) mostra que nesse ir e vir de reflexão e de ação há uma oportunidade de desenvolvimento profissional para o professor. $\mathrm{E}$ Ceres faz a seguinte reflexão:

Veja só, na minha
formação, nós não
tivemos uma disciplina
que tivesse foco na
Matemática, nem tão
pouco na questão da

estatística, para trabalhar com as crianças. [...].

Então, assim, a matemática não foi, durante esse processo, um foco para mim. Mas, assim, sempre fiquei intrigada com muitas questões que eu sentia dúvida com muitas questões que eram trabalhadas em sala de aula com as crianças e que eu percebia que daquela maneira, a criança não ia conseguir aprender. Então, eu tinha muito assim, esse questionamento em mim, com relação ao trabalho da matemática em sala de aula e voltando aqui para Estatística, despertei mais, tanto o interesse quanto o gosto. Muito motivada em conhecer mais, entender melhor, o trabalho que precisa ser realizado, sobre o conhecimento da com as crianças a partir do momento que eu comecei a participar das formações oferecidas pelo GPEMEC na Escola Fé e Alegria. Então, assim, eu acho que eu tive um salto, durante esses quatro anos que eu tenho participado da formação e das questões da estatística, tem muitas coisas ainda que eu acho que já respondi em uma pergunta anterior, que ainda, eu preciso estudar mais, que eu preciso compreender mais, mas assim os próprios momentos de formação são momentos assim bem reflexivos, momentos também assim que a formação traz para gente situações concretas para que a gente possa compreender melhor e trabalhar com os alunos. Então, assim, eu vou me refazendo nesses momentos em leituras 
também que eu preciso fazer à parte, faço algumas leituras também à parte, para poder dar o suporte ao professor, mas, the digo, cada vez mais e me dá um pouco de angústia porque parece que quanto mais a gente lê, quanto mais busca, parece que vai surgindo outras questões, e a gente vai correndo, sempre cada vez mais atrás (Ceres, Entrevista).

Este depoimento de Ceres contempla uma lacuna da sua formação inicial que pode ser sanada na formação continuada, quando fala que não teve acesso ao conhecimento específico da Matemática, "na minha formação, nós não tivemos uma disciplina que tivesse foco na Matemática" (Ceres, Entrevista). A formação de professor é um processo contínuo que não se esgota na formação inicial, logo, é natural que durante sua carreira, nos cursos de formação continuada o professor ou coordenador perceba que está preenchendo uma lacuna daquele primeiro momento (MARCELO GARCIA, 1999).

Sua preocupação com o aprendizado se mostra na fala: "[...] sentia dúvida com muitas questões que eram trabalhadas em sala de aula com as crianças e que eu percebia que daquela maneira, a criança não ia conseguir aprender [...]" (Ceres, Entrevista). Essa preocupação revela a compreensão de Ceres a respeito da ideia de que a pedagogia é a dimensão instrumental do ensino e coordena os meios para alcançar seus objetivos, por tanto, não pode ser fruto de improviso, é necessário conhecer suas bases (TARDIF, 2001).

Ao declarar que sua participação, nas formações oferecidas pelo grupo de pesquisa, tem lhe rendido frutos de aprendizado e que a formação tem cumprido o papel de fonte de conhecimento para ela e o professor. Quando ela mesma mostra que os momentos de formação são "momentos muito reflexivos", o que nos traz à mente a ideia de Marcelo Garcia (1999), sobre a formação como processo contínuo, com os pares e na escola.

Eu vejo que eu busco muito, eu me questiono muito, eu me angustio também principalmente com o número de crianças que às vezes não aprendem, Então é essa minha inconformação diante de muitas questões que a gente não consegue dar conta num ambiente escolar, me impulsiona muito a buscar a estudar cada vez mais, então, eu vejo assim o meu desenvolvimento

profissional dentro, da escola, como algo que está sempre avançando, mas assim sempre eu acho que ainda preciso saber mais ainda preciso conhecer mais, para poder orientar melhor, [...]. Por mais que a gente tenha avançado, ainda temos crianças que a gente não consegue fazer com que elas avancem. Então, essas crianças, esses dados, da não aprendizagem nos impulsiona, no mínimo, impulsiona a buscar, a querer, a estudar e isso vai cada vez mais alimentando o meu conhecimento enquanto profissional, então, eu quero sempre desejar mais para que eu possa me aprofundar cada vez mais nas questões que me incomodam e poder melhorar essas questões (Ceres, Entrevista).

Ceres se declara inconformada como o insucesso de alguns alunos, o que na verdade é parte de seu trabalho e uma das categorias elencada por Shulman (1987) e Marcelo Garcia (1999) em relação à base do conhecimento para o ensino. Com o conhecimento dos estilos e características de aprendizagem dos alunos, a coordenadora vai poder ajudar os professores a realizarem as adequações necessárias aos conteúdos e metodologias para alcançar o almejado sucesso na aprendizagem das crianças e jovens.

Apesar de reconhecer os avanços, Ceres relata que vê as dificuldades de alguns dos alunos como impulso às suas buscas e percebe essas dificuldades como fonte de estímulo ao seu próprio desenvolvimento para melhorar seu trabalho com os professores. Diz: "[...] eu vejo assim o meu desenvolvimento profissional 
dentro, da escola, como algo que está sempre avançando, mas assim sempre eu acho que ainda preciso saber mais ainda preciso conhecer mais para poder orientar melhor [...]" (Ceres, Entrevista).

Tozetto e Kailer (2009) declaram que as ações do coordenador pedagógico não estão desvinculadas das atividades docentes, e não são dotadas de neutralidade política, logo, quando trabalha para diminuir o insucesso dos alunos, através de seu próprio aprendizado, Ceres está lutando por melhoria social. Assim, não se pode esperar que a formação inicial e continuada irá resolver os problemas da educação, pois muitas situações do ensino e da aprendizagem são específicas das localidades e ficam melhor resolvidos com a formação na escola e aproximação da Universidade nesse contexto, o que é muito contemplado na fala de nossa participante.

Ao declarar que, ainda, há crianças que permanecem com dificuldades e mostrar que entende os encontros formativos como lugar para dirimir dúvidas e perceber novos aprendizados, Ceres evidencia a importância da formação não só para ela, como também para o professor e para a promoção do desenvolvimento profissional e justiça social, como a soma de todos esses fatores, como parte das condições de trabalho necessárias para o bom desempenho do professor em sua tarefa de promover a aprendizagem a seus alunos (DAY, 2001).

\section{CONCLUSÕES}

O movimento realizado na escola para promover o desenvolvimento profissional dos professores e, também, da gestão mostra uma visão aproximada dos estudos realizados por Marcelo Garcia (1999), Day (2001) e Imbernón (2011) no que diz respeito ao desenvolvimento profissional de professores, visto que Tália e Ceres concordam e valorizam o conhecimento do professor e a escola como local de formação contínua e aprendizagens. Suas ideias nos fazem crer que essa visão é fruto de planejamento da escola realizado em colaboração, e não questões individuais.

Quando Tália e Ceres falam em garantir ou permitir a formação na escola e dentro da carga horária do professor, estão na verdade defendendo que o profissional tenha tempo para essa formação. Ao defender o que chamam de formação continuada na escola, estão buscando garantir não só a formação, mas também 0 espaço para que possam discutir e colocar em prática essa formação e a reflexão da prática.

Por meio do diálogo, os professores participam e valorizam a formação. Assim, Tália e Ceres cumprem o papel de oferecer aos docentes a formação continuada que necessitam, naquele momento, para avançar na busca da melhoria do seu conhecimento, da aprendizagem do aluno e do seu desenvolvimento profissional. Ao participar da formação oferecida pelo GPEMEC, Ceres se coloca como alguém que também está aprendendo, o que permite ao professor vê-la como alguém que pode lhe ajudar nos momentos de dúvida em relação ao planejamento e a organização das ações a serem desenvolvidas com os conteúdos de Matemática.

Essa participação acontece nos momentos de planejamento, principalmente nos encontros de A.C, em que Ceres é procurada pelos professores, quando esses têm alguma dúvida ou inseguranças a respeito de um conceito Matemático (estatístico). Nessas oportunidades, Ceres além ajudar com o entendimento dos conhecimentos da matéria, pode também auxiliar com o conhecimento pedagógico. Além de fazê-lo, ainda costuma agregar uma terceira pessoa ao diálogo quando solicita a participação de um professor que demonstra ter mais segurança com o conteúdo, fortalecendo assim na escola a cultura de colaboração entre os professores, bem como entre eles e a gestão.

Podemos então, entender que o movimento proposto pela gestão escolar para o desenvolvimento profissional dos docentes na escola é o de permitir, garantir, incentivar, participar e aproximar seus professores das fontes externas de formação, como Universidade e grupos de pesquisa, valorizando a cultura de colaboração na instituição, como local de ensino e da aprendizagem e das propostas apresentadas no Projeto Pedagógico da Escola.

\section{REFERÊNCIAS}

ANDRÉ, M. Formar o professor pesquisador para um novo desenvolvimento profissional. In: ANDRÉ, M. (Org.). Práticas inovadoras na formação de professores. São Paulo: Papirus, 2016.

BOGDAN, R.; BIKLEN, S. Investigação qualitativa em educação: uma introdução à teoria dos métodos, Porto: Porto Editora, 1994. 
BRASIL. Ministério da Educação. Diretrizes Curriculares Nacionais da Educação Básica. Brasília, DF. 2013. Disponível em: http://portal.mec.gov.br/index.php?option=com docman\&view=download\&alias $=13448$ diretrizes-curiculares-nacionais-2013pdf\&Itemid=30192. Acesso em: 5 de nov. 2019.

BRASIL. Ministério da Educação. Lei n. 9394/96. Brasília, DF, 1996. Disponível em: http://www.planalto.gov.br/ccivil_03/leis/19394. htm. Acesso em: 15 jan. 2019.

DAY, C. Desenvolvimento profissional de profesores: 0 desafio da Aprendizagem permanente. Porto: Porto Editora, 2001.

ILHÉUS. Parecer CME/CLN № 001/2017. Ilhéus, 2017. Disponível em: www.ilhéus.ba.gov.br Acesso em 11 abr. 2020.

ILHÉUS. Plano de carreira do Magstério Público Municipal de llheus e Estatuto do Magistério. Ilhéus, 2002. Disponível em: https://leismunicipais.com.br/a/ba/i/ilheus/leiordinaria/2002/300/3001/lei-ordinaria-n-30012002-dispoe-sobre-o-plano-de-carreira-domagisterio-publico-municipal-de-ilheus-e-daoutras-providencias. Acesso em 11 abr. 2020.

IMBERNÓN, F. Formação docente e profissional: forma-se para a mudança e incerteza. São Paulo: Cortez, 2011.

LIBÂNEO, J. C. Organização e Gestão da Escola: teoria e prática. São Paulo: Heccus, 2013.

LIBÂNEO, J. C; OLIVEIRA, J. F; TOSHI, M. S. Educação escolar: políticas, estrutura e organização. 10. ed. São Paulo: Cortez, 2012.

LOPES, C. E. O ensino de Estatística e da Probabilidade Educação Básicca e a Formação de Professores. Cad. Cedes, Campinas, v. 28, n. 28, p. 57-73, 10, Janeiro, 2008. Disponivel em: https://www.scielo.br/scielo.php?script=sci artte xt\&pid=S0101-32622008000100005. Acesso em: 17 set. 2019. DOI:10.1590/S0101$\underline{32622008000100005}$

MARCELO GARCIA, C. Formação de Professores: para uma mudança educativa. Porto: Porto Editora, 1999.
PLACCO, V. M. N. S; SOUZA, V. L. T; ALMEIDA, L.R. O Coordenador Pedagógico: Aporte à proposição de políticas públicas. Cadernos de Pesquisa, São Paulo, v. 42, n. 147, p. 754-771, set./dez. 2013. Disponível em: https://www.scielo.br/scielo.php?script=sci artte xt\&pid=S0100-

15742012000300006\&lng=pt\&tlng=pt. Acesso em: 8 dez. 2020. DOI:10.1590/S0100$\underline{15742012000300006}$

SCHÖN, D. Educando o professional reflexivo. Um novo design para o ensino e aprendizagem. Porto Alegre: ArTmed, 2000.

SHULMAN, L. S. Those who understands: knowledge growth in teaching. Educational Researcher, Washington, v. 15, n. 2, p. 4-14, $1986 . \quad$ Disponível em: https://journals.sagepub.com/doi/10.3102/0013 189X015002004. Acesso em: 08 dez. 2020. DOI:10.3102/0013189X015002004

SHULMAN, L. S. Knowledge and Teaching Foundations of the New Reform, a Harvard Educational Review, v. 57, n. 1, p. 1-22, primavera 1987. (Tradução de Leda Beck e revisão técnica de Paula Louzano). Disponível em: https://meridian.allenpress.com/her/articleabstract/57/1/1/31319/Knowledge-and-

Teaching-Foundations-of-the-

New?redirectedFrom=fulltext. Acesso em: $08 \mathrm{dez}$. 2020.DOI:10.17763/haer.57.1.j463w79r56455411

SHULMAN, L. S. Conhecimento e ensino: fundamentos para a nova reforma. Cadernos Cenpec, São Paulo, v. 4, n. 2, p. 196-229, dez., $2014 . \quad$ Disponível em: https://www.google.com/url?sa=t\&rct=j\&q=\&esr $\mathrm{c}=\mathrm{s} \&$ source $=$ web\& $\mathrm{cd}=\&$ ved $=2 \mathrm{ahUKEwjQ9KyD1b7}$ tAhVoJ7kGHUjVBp0QFjAAegQIARAC\&url=https\% 3A\%2F\%2Fsigeve.ead.unesp.br\%2Findex.php\%2F submission\%2FdownloadFileProceedings\%2F187 3\&usg=AOvVaw28BL36wuXJMwOd3Pfd gDt. Acesso em: 08 dez. 2020. DOI:10.18676/2237$\underline{998322014293}$

SPINK, M. J. P.; MEDRADO, B. Produção de sentido no cotidiano: uma abordagem teóricometodológica para análise de práticas discursivas. In: SPINK, Mary Jane P. (org.). Práticas discursivas e produção de sentidos no cotidiano. Rio de 
Janeiro: Centro Edelstein de pesquisas sociais, 2013. p. 41-61.

SPINK, M. J. P.; MENEGON, V. M. A pesquisa como prática discursiva: superando os horrores metodológios. In: SPINK, Mary Jane P. (org.). Práticas discursivas e produção de sentidos no cotidiano. Rio de Janeiro: Centro Edelstein de pesquisas sociais, 2013. p. 63-92.

TARDIF, M. 0 trabalho docente, a pedagogia e o ensino. 7. ed. Rio de Janeiro: Vozes, 2001.

TOZETTO, S. S; KAILER, P. G. L. O espaço da formação inicial do coordenador pedagógico. Espaço Pedagógico, Passo Fundo, v. 26, n. 3, p. 857-880, set./dez. 2019. Disponível em: www.upf.br/seer/index.php/re. Acesso em: 01 dez. 2019. DOl:10.5335/rep.v26i3.7262 